Endocrinol. Japon. 1960, 7 (2), 109 120

\title{
GORRELATION BETWEEN GLUCOSE BASAL UPTAKE AND INSULIN EFFECT IN RAT-DIAPHRAGM METHOD
}

\author{
ISAMU SUNAGA, SETSUYA TAKEUCHI \\ AND KATSUHIRO SHIBATA \\ Department of Pharmacology, School of Medicine, \\ Gunma University, Maebashi
}

For the microdetermination of insulin, various biological standardizations have been attempted. Recently the application of the rat-diaphragm method was introduced (Vallance-Owen and Hurlock, 1954; Randle, 1954; Takeuchi et al., 1957a). The advantage of this latter over others is that the minimum detectable concentration is very low; that is, $0.01-0.001 \mathrm{mU}$ per $\mathrm{ml}$ can be detected. The results obtained by many investigators, however, are not always in agreement with each other, for the insulin activity in plasma as well as for the properties of the log dose response curve which is applied to the bioassay of insulin. This seems to indicate that, in the determination by this method up to the present, each detail of the procedure has not been perfectly followed under optimal conditions. Lately, one of the authors, Takeuchi (1958), published the results of a detailed investigation on these points, but nevertheless they are not yet completely clarified. Now with the object of establishing a consistent and reliable estimation by the diaphragm method, some investigations have been carried out from the viewpoint that the basal uptake and the insulin effect must be correlated with each other, and consequently that there must be an intimate relationship between various experimental conditions. The present paper is intended to outline these experiments, which revealed some facts of interest.

\section{MATERIALS AND METHODS}

Experimental animals Wistar strain rats, propagated and bred in the author's laboratory, and weighing $90-110 \mathrm{~g}$, were used. They were housed in cages maintained above $20^{\circ} \mathrm{C}$, and were principally given the standard solid food (containing $51 \%$ carbohydrate, $5.6 \%$ fat and $25 \%$ protein as dry ingredients). For some animals, high carbohydrate food was used, that is, $30 \mathrm{~g}$ of paste made of wheat and water, $1 \mathrm{~g}$ of dried fish and $20 \mathrm{~g}$ of vegetable (containing $75 \%$ carbohydrate, $30 \%$ fat and $10 \%$ protein as dry ingredients), which was given once daily. The former was designated as balanced diet, and the latter as high carbohydrate.

Preparation of diaphragm The animals, fed the above mentioned food for 1 week, were fasted for $24 \mathrm{hrs}$, and then killed by decapitation to take out the diaphragm. For the preparation of diaphragms, the pooled method of the hemidiaphragm technique was followed as described by Takeuchi et al. (1957a). Incubation was performed in the Warburg apparatus, using as medium $2 \mathrm{ml}$ of Krebs-Ringer-phosphate buffer ( $\mathrm{pH} 7.4$ ) which contained $0.032 \%, 0.100 \%, 0.200 \%$ and $0.316 \%$

Received for publication January 30, 1960. 
glucose. Standard insulin solution was prepared by dissolving insulin crystals with a potency of $24.8 \mathrm{U} / \mathrm{mg}$ (Shimizu Pharmaceut. Co.) in acetic acid. This was added to the above mentioned medium to 100,10 and $1 \mathrm{mU} / \mathrm{ml}$. Gas phase was $100 \% \mathrm{O}_{2}$. After 90 mins. incubation, glucose concentration in the incubation medium was determined by the Somogyi-Nelson's micromethod (Somogyi, 1945), when oxygen consumption was below $2.00 \mu \mathrm{l} / \mathrm{mg}$ of wet tissue/hr. Employing the following formulae, diaphragm glucose uptake and insulin effect were computed:

Basal uptake $(\mathrm{mg} / 100 \mathrm{mg}$ of wet tissue/hr. $)=\frac{\mathrm{M}_{1}-\mathrm{M}_{2}}{\mathrm{Wt}} \times \frac{4}{3}$

$\mathrm{M}_{1}$ : Glucose concentration before incubation ( $\mathrm{mg} \%$ )

$\mathrm{M}_{2}$ : Glucose concentration after incubation ( $\mathrm{mg} \%$ )

Insulin effect $(\mathrm{mg} / 100 \mathrm{mg}$ of wet tissue/hr. $)=$ Glucose uptake with insulin added - Basal uptake

\section{RESULTS}

Observation 1. Correlation beiween the basal uptake and the insulin effect Diaphragms from 96 rats fed the high carbohydrate diet and 84 rats fed the balanced diet were incubated in the media with glucose concentration of $0.200 \%$, to which was added insulin to 100,10 and $1 \mathrm{mU} / \mathrm{ml}$, respectively, and the basal uptake and insulin effect were determined. Estimations were plotted in Figures $1 \sim 3$, the former on the abscissa, and the latter on the ordinate. Results with different insulin concentrations are separately presented, and in all, regression was expressed as follows: When insulin and glucose concentration were both constant, values obtained tended to be arranged along a line in all the cases, and the insulin effect was extremely small against relatively low basal uptake, but abruptly increased when the latter was somewhat elevated. When, however, the basal uptake was above a certain level, increase in insulin effect could no more be observed, but it rather tended to fall gradually, and in diaphragm samples which showed relatively greater basal

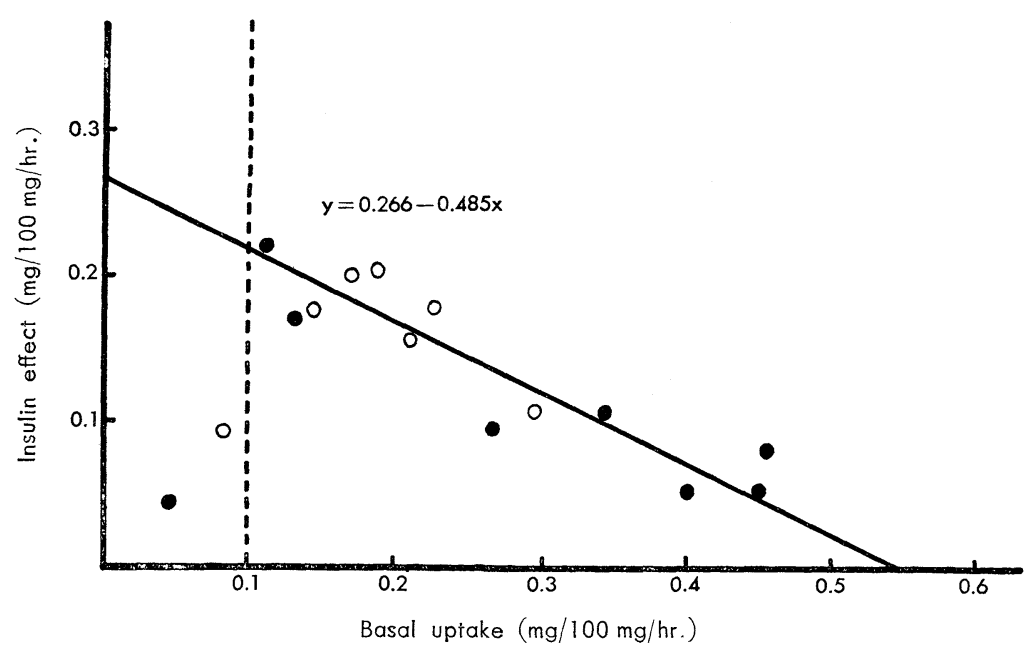

Fig. 1. Correlation line between the basal uptake and the insulin effect (Medium concentration of glucose, $0.2 \%$; that of insulin, $100 \mathrm{mU} / \mathrm{ml}$ )

Balanced diet group

- High carbohydrate diet group 


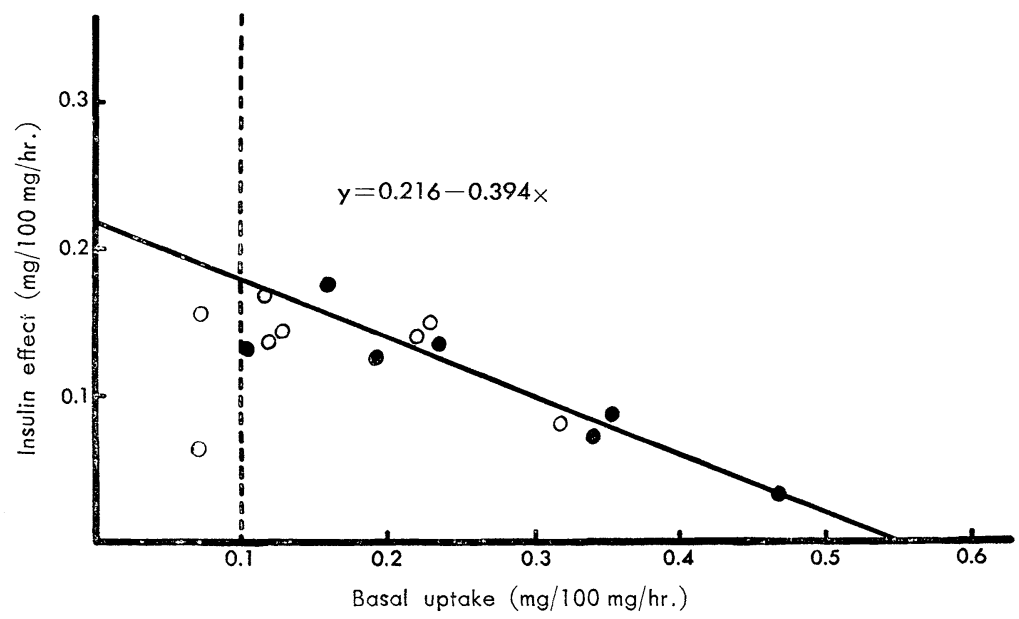

Fig. 2. Ccrrelation line between the basal uptake and the insulin effect (Medium concentration of glucose, $0.2 \%$; that of insulin, $10 \mathrm{mU} / \mathrm{ml}$ )

B lanced diet group

- High carbohydrate diet group

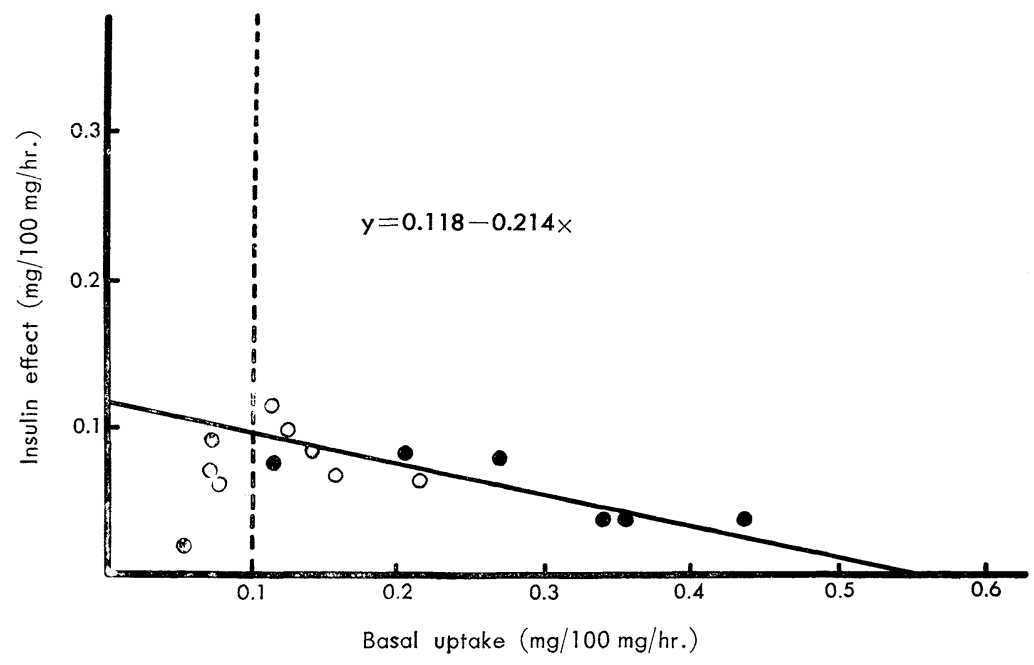

Fig. 3. Correlation line between the basal uptake and the insulin effect (Medium concentration of glucose, $0.2 \%$; that of insulin, $1 \mathrm{mU} / \mathrm{ml}$ )

$\mathrm{B}$-lanced diet group

- High carbohydrate diet group

uptake, only a small insulin effect was demonstrated. The basal uptake against which the insulin effect attained the turning point, that is, the maximum point, seemed to be nearly $0.1 \mathrm{mg} / 100 \mathrm{mg} / \mathrm{hr}$, regardless of concentration of added insulin, when the medium contained $0.200 \%$ glucose. The cases in which basal uptake was below A/2 mg/100 $\mathrm{mg} / \mathrm{hr}$. (A: glucose concentration in the medium, \%) were omitted to simplify the com- 
putation, since their frequency was small. In these cases, linear regression is confirmed to be significant against deviation from regression $(\mathrm{p}<0.05)$, that is, $\mathrm{F}=80.9$ when insulin concentration is $100 \mathrm{mU} / \mathrm{ml}, \mathrm{F}=26.2$ when it is $10 \mathrm{mU} / \mathrm{ml}$, and $\mathrm{F}=39.2$ when it is $1 \mathrm{mU} / \mathrm{ml}$.

Observation 2. Relation of insulin concentration to correlation line between the insulin effect and the basal uptake To compare the properties of the regression lines represented in Figures $1 \sim 3$, the following points were taken into consideration:

The value of $x$ at $y=0$, that is, at the intersection of the $x$-axis and the regression line. This denotes the maximum basal uptake to be exhibited by the diaphragm, and theoretically it is impossible to obtain greater values than this, no matter how much insulin may be added. This was designated as calculated maximum basal uptake (MBUcal.).

The value of $y$ at $x=0$, that is, at the intersection of the regression line and the y-axis. This denotes the maximum insulin effect, and was designated as calculated maximum insulin effect (MIEcal.). Table 1 gives MBUcal., MIE cal, and absolute value of the regression coefficient $(|\mathrm{b}|)$ for each regression line.

Table 1. Properties of correlation lines between the basal uptake and the insulin effect in incubation medium containing different concentrations of glucose and insulin

\begin{tabular}{|c|c|c|c|c|c|}
\hline \multicolumn{2}{|c|}{$\begin{array}{c}\text { Concentrations in incubation } \\
\text { medium }\end{array}$} & \multirow{2}{*}{$\begin{array}{c}\text { Linear regression } \\
\text { of correlation } \\
\text { curve (F) }\end{array}$} & \multicolumn{3}{|c|}{ Coefficients in correlation line } \\
\hline Glucose (\%) & Insulin $(\mathrm{mU} / \mathrm{ml})$ & & MBUcal. & MIEcal. & $|b|$ \\
\hline 0.200 & 100 & $80.9^{* *}$ & 0.548 & 0.266 & 0.485 \\
\hline 0.200 & 10 & $26.2^{* *}$ & 0.548 & 0.216 & 0.394 \\
\hline 0.200 & 1 & $39.2^{* *}$ & 0.551 & 0.118 & 0.214 \\
\hline 0.316 & 10 & $5.7^{*}$ & 1.011 & 0.265 & 0.262 \\
\hline 0.100 & 10 & $15.6^{* *}$ & 0.385 & 0.238 & 0.617 \\
\hline 0.032 & 10 & 3.8 & $(0.108)$ & $(0.240)$ & $(2.222)$ \\
\hline
\end{tabular}

As for MBUcal., the relation between this value and added insulin concentration was found as follows: Either when the concentration was $100 \mathrm{mU} / \mathrm{ml}$ or when it was $10 \mathrm{mU} / \mathrm{ml}$, MBUcal. was always $0.548 \mathrm{mg} / 100 \mathrm{mg} / \mathrm{hr}$., and when the former was $1 \mathrm{mU} / \mathrm{ml}$, the latter was $0.551 \mathrm{mg} / 100 \mathrm{mg} / \mathrm{hr}$., which is nearly equal to the above mentioned. Thus, it was apparent that when the glucose concentration in the medium was constant, MBUcal. was also nearly constant regardless of added insulin concentration. As to the relation of insulin concentration to MIEcal. and $|\mathrm{b}|$, the latter 2 decreased with decrease of the former. Namely, when insulin concentration was $100 \mathrm{mU} / \mathrm{ml}$, MIEcal. and $|\mathrm{b}|$ were $0.266 \mathrm{mg} / 100 \mathrm{mg} / \mathrm{hr}$. and 0.485 , respectively, which gradually decreased to $0.216 \mathrm{mg} / 100 \mathrm{mg} / \mathrm{hr}$. and 0.394 , and $0.118 \mathrm{mg} / 100 \mathrm{mg} / \mathrm{hr}$. and $0.2 \mathrm{I} 4$, as the concentration decreased to $10 \mathrm{mU} / \mathrm{ml}$ and $1 \mathrm{mU} / \mathrm{ml}$. Consequently, when glucose concentration in the medium is kept constant and only added insulin concentration is varied, the resulting regression lines present a radial form with MBUcal. as the center.

It is considered that the absolute value of regression coefficient $(|b|)$ can be 
used as the metameter of the response in insulin determination by the rat-diaphragm method, since it is approximately proportional to added insulin concentration, and all the regression lines between the basal uptake and the insulin effect obtained with varying insulin concentrations pass the fixed point (MBU cal.). Hereupon this metameter was compared with the one hitherto used, that is to say, insulin effect itself. For this purpose, experiments were performed with the diaphragm from rats which were fed the balanced diet, and the medium containing $0.200 \%$ glucose to which was added insulin to $100,10,1$ and $0.1 \mathrm{mU} / \mathrm{ml}$. The log-concentration response curve, obtained with insulin effect and logarithm of insulin concentration, showed a linear regression (broken line in Fig. 4) with standard deviation $s=0.280$, regression coefficient $\mathrm{b}=+0.608$, and index of precision (Bliss, 1952) $\lambda=0.461$. When metameters were logarithm of insulin concentration and absolute values of regression coefficients of the correlation lines at insulin concentrations of 100,10 and $1 \mathrm{mU} / \mathrm{ml}$, the regression line (solid line in Fig. 4) gave the following values: $s=0.212, b=+1.345, \lambda=0.158$.

Observation 3. Relation of glucose concentration in the medium to correlation line between the insulin effect and the basal uptake The basal uptake and the insulin effect were determined with diaphragms from 172 rats, fed the balanced diet, glucose concentrations of $0.316,0.100$ and $0.032 \%$, and constant insulin concentration of $10 \mathrm{mU} / \mathrm{ml}$. Figures 5 7 represent regression lines at different glucose concentrations, the cases in which basal uptakes below $\mathrm{A} / 2 \mathrm{mg} / 100 \mathrm{mg} / \mathrm{hr}$. being omitted as afore described. F, MBUcal., MIEcal. and $|\mathrm{b}|$ for these linear regressions are given in Table $1 . \quad F$ is 5.7 and 15.6 at glucose concentrations $0.316 \%$ and $0.100 \%$, respectively, which are significant against deviation from regression $(\mathrm{p}<0.05)$. At glucose concentration $0.032 \%, \mathrm{~F}$ is 3.8 , and therefore linear regres- 
Table 2. The bescl uptake and insulin effect by the diaphragm from rats given the balanced diet and high carbohydrate dier

\begin{tabular}{|c|c|c|c|c|}
\hline \multicolumn{2}{|c|}{ Treaimeni } & \multirow[b]{2}{*}{$\begin{array}{l}\text { No. of } \\
\text { tests }\end{array}$} & \multirow{2}{*}{\multicolumn{2}{|c|}{$\begin{array}{l}\text { Glucoss upiake by diaphragm } \\
\text { Basal upiake Insulin effect }\end{array}$}} \\
\hline Diet & $\begin{array}{l}\text { Insulin concent. } \\
\text { in incubariion } \\
\text { medium }(\mathrm{mU} / \mathrm{ml})\end{array}$ & & & \\
\hline High carbohydraie & 100 & 8 & $0.275 \pm 0.160$ & $0.118 \pm 0.064$ \\
\hline Balanced & & 7 & $0.186 \pm 0.067$ & $0.161 \pm 0.044$ \\
\hline High carbohydraie & 10 & 8 & $0.238 \pm 0.147$ & $0.103 \pm 0.046$ \\
\hline Balanced & & 7 & $0.171 \pm 0.111$ & $0.135 \pm 0.023$ \\
\hline High carbohydraie & 1 & 8 & $0.229 \pm 0.141$ & $0.058 \pm 0.033$ \\
\hline Balanced & & 7 & $0.200 \pm 0.049$ & $0.081 \pm 0.019$ \\
\hline
\end{tabular}

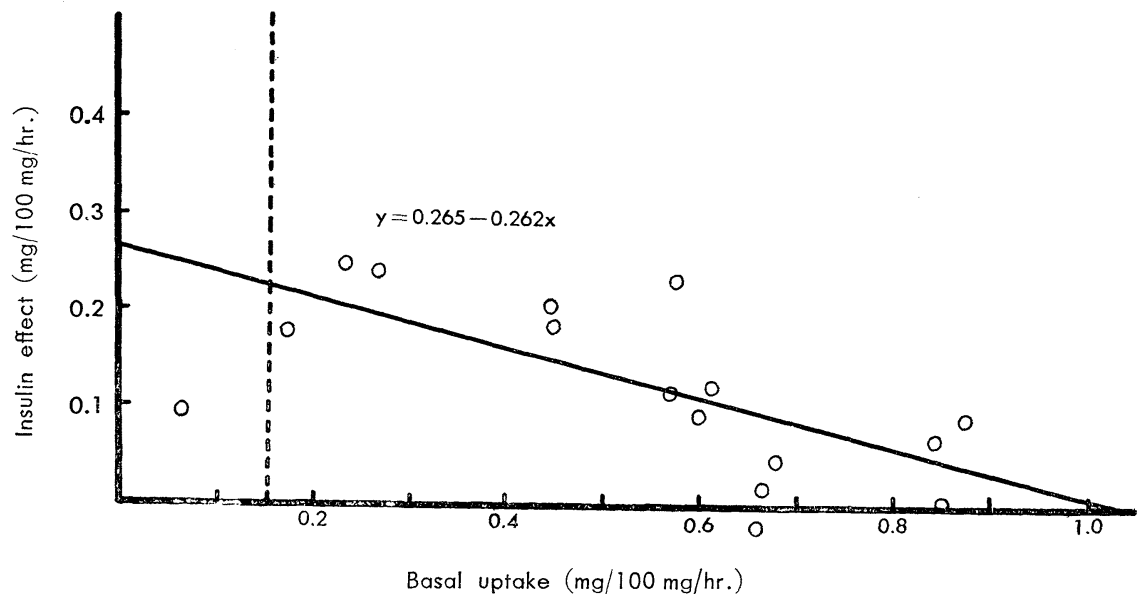

Fig. 5. Correlation line between the basal uptake and insulin effect (Medium concentration of glucose, $0.316 \%$; that of insulin, $10 \mathrm{mU} / \mathrm{ml}$ )

sion is not significant.

The comparison between results at glucose concentrations $0.316 \%$ and $0.100 \%$ and those at $0.200 \%$ in observation 2 shows that while there are remarkable differences in MBUcal. and $|\mathrm{b}|$, there is only slight difference in MIEcal. MBUcal. is $1.011 \mathrm{mg} / 100 \mathrm{mg} / \mathrm{hr}$. at glucose concentration $0.316 \%, 0.548 \mathrm{mg} / 100 \mathrm{mg} / \mathrm{hr}$. at $0.200 \%$, and $0.385 \mathrm{mg} / 100 \mathrm{mg} / \mathrm{hr}$. at $0.100 \%$, showing in this way a persistent decrease; and b| was $0.262,0.394$ and 0.617 at glucose concentration $0.316 \%, 0.200 \%$ and $0.100 \%$, respetively; that is, a progressively increasing slope. By contrast to these remarkable differences in the above 2 values, MIEcal. was $0.265,0.216$ and $0.238 \mathrm{mg} / 100$ $\mathrm{mg} / \mathrm{hr}$. at glucose concentration $0.316 \%, 0.200 \%$ and $0.100 \%$, respectively, thus showing only slight difference. Consequently, the regression lines obtained with constant insulin concentration and varying glucose concentrations exhibit a radial form with the center at a certain MIEcal.

When glucose concentration was $0.032 \%$, linear regression was not significant. However, this does not conflict with the results obtained in higher glucose con- 


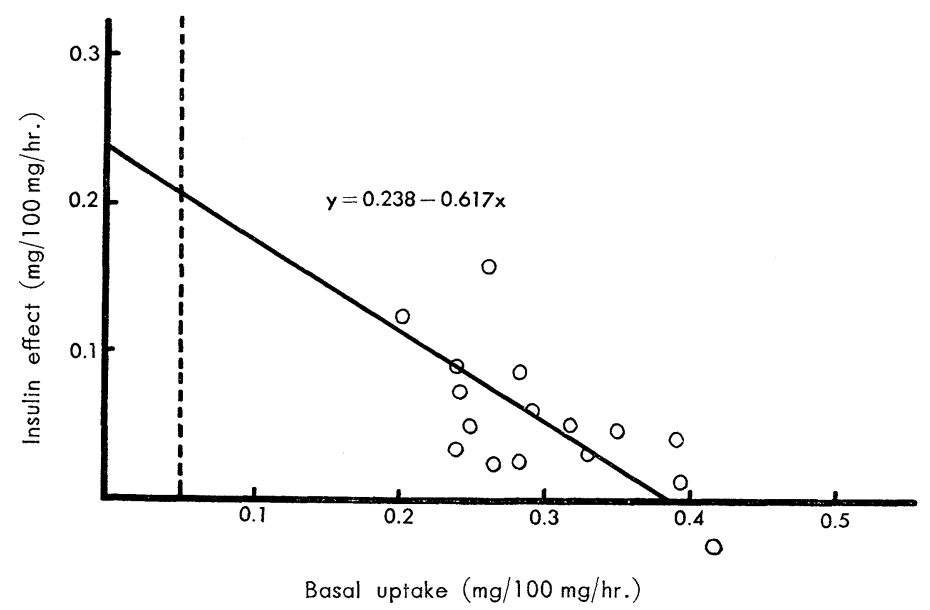

Fig. 6. Correlation line between the basal uptake and insulin effect (Medium concentration of glucose, $0.1 \%$; that of insulin, $10 \mathrm{mU} / \mathrm{ml}$ )

centrations, since the sensitivity of Somogyi-Nelson's method is not sufficient for such low concentrations and the error in determination is too great to obtain a significant regression. The line in Figure 7 was obtained by taking the average for MIEcals. at the other glucose concentrations as the origin, and by plotting minimal distances from corresponding measured points. The parenthesized figures in Table 1 show MBUcal., MIEcal. and $|\mathrm{b}|$ obtained from this graph.

What is further known from the above results is that with increase in glucose concentration in the medium, MBUcal. also seems to increase, indicating a proportional relation between them. Figure 8, in which glucose concentration is

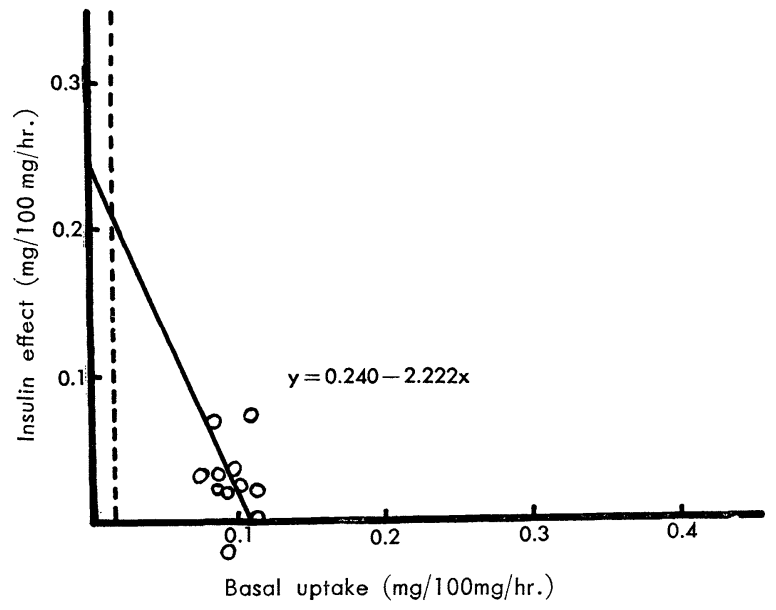

Fig. 7. Correlation line between the basal uptake and insulin effect (Medium concentration of glucose, $0.032 \%$; that of insulin, $10 \mathrm{mU} / \mathrm{ml}$ ) measured on the ordinate, and MBUcal. on the abscissa, represents the correlation between these 2 at insulin concentration $10 \mathrm{mU} /$ $\mathrm{ml}$. It passes the origin, and is expressed by the formula, $3.11 \mathrm{~A}=\mathrm{MBU}$ cal. (A: Glucose concentration in the medium, \%).

Observation 4. Effect of the composition of diet The basal uptake and the insulin effect were determined with diaphragms from 96 rats given the high carbohydrate diet and from 84 rats given the balanced diet, at glucose concentration in the me- 


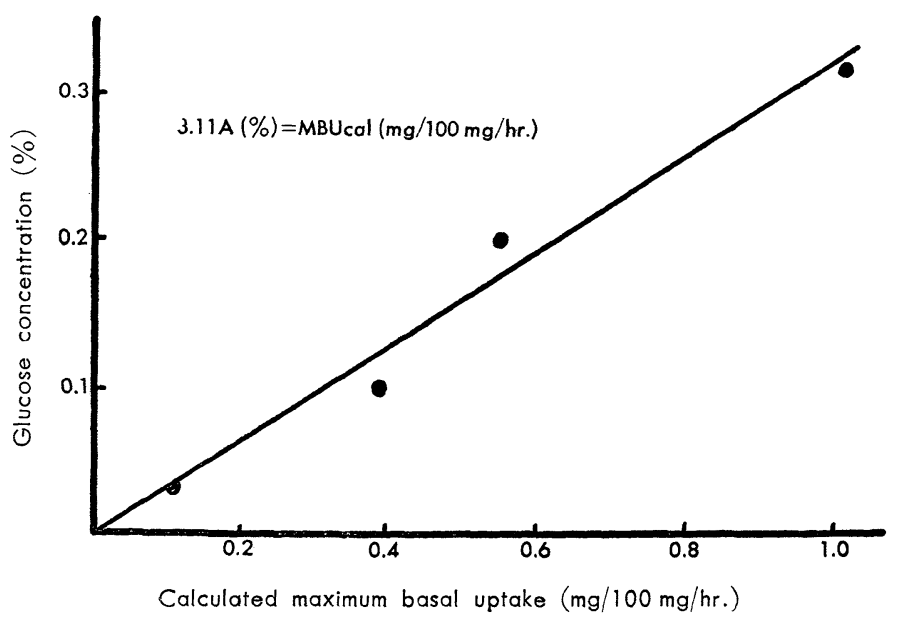

Fig. 8. Relation between MBUcal. and medium concentration of glucose. A: glucose concentration, $\%$

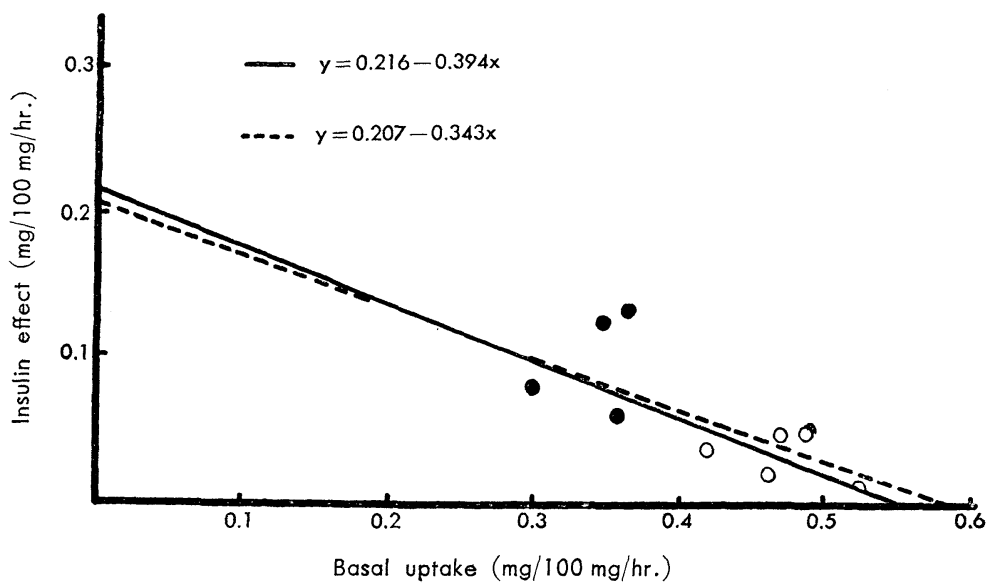

Fig. 9. Correlation lines between the basal uptake and the insulin effect (Medium concentration of glucose, $0.2 \%$; that of insulin, $10 \mathrm{mU} / \mathrm{ml}$ )

Solid line: Regression line computed from the data in high carbohydrate diet group and balanced diet one.

Broken line: That in insulin-pretreated (O) and non-treated (0) groups.

dium of $0.200 \%$, and added insulin concentrations 100,10 and $1 \mathrm{mU} / \mathrm{ml}$. The results are compared in Table 2 . The average basal uptake by the balanced diet group ranged $0.171 \sim 0.200 \mathrm{mg} / 100 \mathrm{mg} / \mathrm{hr}$. as against $0.229 \sim 0.275 \mathrm{mg} / 100 \mathrm{mg} / \mathrm{hr}$. by the high carbohydrate one, while the insulin effect was always lower in the former than in the latter. At insulin concentration $100 \mathrm{mU} / \mathrm{ml}$, it was 0.118 in the former as against $0.161 \mathrm{mg} / 100 \mathrm{mg} / \mathrm{hr}$. in the latter, and at 10 and $1 \mathrm{mU} / \mathrm{ml}$ 0.103 and $0.058 \mathrm{mg} / 100 \mathrm{mg} / \mathrm{hr}$. in the former as against 0.135 and $0,081 \mathrm{mg} / 100 \mathrm{mg} / \mathrm{hr}$, 
in the latter, respectively. When, however, standard deviations are compared, the high carbohydrate diet group always showed higher (2 to 3 times) values than the balanced diet one. For the basal uptake at insulin concentration $1 \mathrm{mU} / \mathrm{ml}$, the standard deviation was 0.049 in the balanced diet group as against 0.141 in the high carbohydrate diet one, and for the insulin effect at its concentration $10 \mathrm{mU} / \mathrm{ml}$, it was 0.023 in the former as against 0.046 in the latter. This seems to indicate the presence of some other reason than decrease or increase in the basal uptake or the insulin effect. In order to clarify this point, Figures $1 \sim 3$ were investigated, and the following was found. As to the basal uptake, the measured values in the balanced diet group tend to collect in a narrow range in a relatively central part, whereas those in the high carbohydrate diet group are scattered in a wide range extending from below $0.1 \mathrm{mg} / 100 \mathrm{mg} / \mathrm{hr}$. to $0.5 \mathrm{mg} / 100$ $\mathrm{mg} / \mathrm{hr}$. Moreover, deflections of the values due to difference in food occur not as deviation from the regression line but along it. And so the basal uptake by the high carbohydrate diet group shows greater deflection, inducing as a consequence greater deflections in the insulin effect. Hence, it is considered that change in the basal uptake and the insulin effect would occur only within a definite range of correlation between them.

Observation 5. Effects of pretreatment with insulin Forty rats, fed the balanced diet, were divided into 2 groups of 20 each, and 1 group was used as controls, and the other was subcutaneously injected with $0.1 \mathrm{U}$ per rat of insulin. At 30 mins. after the injection, the diaphragms were removed from both groups, and the basal uptake was determined after incubation in the medium with glucose concentration of $0.2 \%$, and the insulin effect after the addition of $10 \mathrm{mU}$ per $\mathrm{ml}$ of insulin. For the controls, the basal uptake averaged $0.368 \pm 0.066 \mathrm{mg} / 100 \mathrm{mg} / \mathrm{hr}$., and the insulin effect $0.096 \pm 0.034 \mathrm{mg} / 100 \mathrm{mg} / \mathrm{hr}$. Against these, the basal uptake for the insulin-pretreated group averaged $0.4 \% 2 \pm 0.033 \mathrm{mg} / 100 \mathrm{mg} / \mathrm{hr}$. and the insulin effect $0.036 \pm 0.013 \mathrm{mg} / 100 \mathrm{mg} / \mathrm{hr}$. In this way, the pretreatment with insulin increased the basal uptake and decreased the insulin effect. Figure 9 was obtained by plotting the values on the respective coordinates. The linear regression of the graph is expressed by the formula $y=0.207-0.343 x$, which is closely similar to the above mentioned $y=0.216-0.394 x$, obtained with glucose concentration $0.2 \%$ and insulin concentration $10 \mathrm{mU}$ per $\mathrm{ml}$. This indicates that the above mentioned change in the basal uptake and the insulin effect by the insulin pretreatment is due to positional change of the observed values along the same regression line.

\section{DISCUSSION}

Since Gemmill's report (1940), many studies have been published on the isolated rat-diaphragm method, because it has drawn attention of workers by its high sensitivity, far exceeding those of other methods (Vallance-Owen and Hurlock, 1954; Randle, 1954; Willebrands and Groen, 1956; Takeuchi et al., 1957a, b). There are, however, considerable discrepancies among the results obtained by various workers, and sometimes divergence is observed even among the results of the same author. This indicates that the result by the diaphragm method is significantly affected by various experimental conditions and procedures, From 
this it naturally follows that detailed investigation for the standard conditions is the prerequisite for the establishment of this method. However, considerable variation in the insulin effect was still observed even after strict control of various conditions such as known in the past literatures (Stadie and Zapp, 1947; Krahl and Park, 1948; Willebrands et al., 1950; Brown et al., 1952; Krahl, 1951; Randle, 1956; Rogers, 1958). The authors performed research into this variation, and found that, in considerable measure, it was secondarily elicited by variation in the basal uptake. It was found that the insulin effect was altered not only by such factors as exert a direct effect on it, but secondarily also by factors which have an influence on the basal uptake. And in search for the way by which change in the basal uptake elicits change in the insulin effect, the correlation between these 2 values became the focus of the attention.

In the present experiments, the determination was made on glucose uptake by diaphragms from animals given high carbohydrate and balanced diet, respectively, and incubated in a medium containing glucose with or without insulin, and the results revealed that there is a linear regression between the basal uptake and the insulin effect within the range of the later $\mathrm{A} / 2 \mathrm{mg} / 100 \mathrm{mg} / \mathrm{hr}$. (A: glucose concentration in the incubation medium, \%) as long as the glucose and insulin concentration in the medium remains constant. Kerly and Ottaway (1954) recognized a linear relation between the basal uptake and per cent increase in the $\Delta$-uptake induced by insulin. They determined the basal uptake and insulin effect at 0,24 and $48 \mathrm{hrs}$. after fasting with diaphragms from rats given highcarbohydrate, high-fat, and high-protein diet, respectively, and demonstrated a linear correlation using averages for each diet group. Kerly and Ottaway's result is not essentially different from the authors except in the metameter. In the authors' result, however, there were cases, though small in number, in which the basal uptake as well as the insulin effect were extremely low, and consequently the determined values lay widely divergent from the regression line. Its cause is not evident, nor can any adequate explanation be found for it. But it can be presumed that there may have been some defect in the preparation of diaphragm which inhibited perfect execution of the basal uptake and the insulin effect, or that owing to relatively low oxygen consumption in these cases, tissue metabolism may have been in a highly depressed state. It is of great interest that such a phenomenon was found more frequently in diaphragms from animals given the high carbohydrate diet.

The correlation line between the basal uptake and the insulin effect altered its regression coefficient when only the concentration of insulin in the medium was changed with that of glucose kept constant, but it always passed a fixed point on the abscissa. On the ground of this fact it was investigated whether the absolute value of the slope $(|\mathrm{b}|)$ can be used as the metameter of insulin determination. And it was found that when this value was used as the metameter for the response to insulin, the index of precision was far smaller than when insulin effect itself was used, which has been routine up to the present. The advantage of this method is that the error, produced secondarily by the effect of the variation of the basal uptake, can be avoided to some extent, whereas such error is unavoidable when the insulin effect was used, The variation in the insulin effect 
due to that in the basal uptake is an alteration along the correlation line, so that it can not affect the absolute value of the slope $(\mathbf{b} \mid)$. However, the error distribution given in observation 2 was not so small as was expected. The reason why $\lambda=\mathrm{s} / \mathrm{b} \mid$ was small is that $|\mathrm{b}|$ became greater rather than that $\mathrm{s}$ became smaller. And s did not become smaller probably because a divergence of determined values from the correlation curve would exert a considerable effect on the error distribution when the basal uptake is relatively greater. On this account, the use of the slope as the metameter can have a still greater advantage if the determination is carried out with diaphragms from animals given the balanced diet, that is the condition under which the basal uptake does not become so great.

When the glucose concentration in incubation medium was altered, a remarkable change was produced in MBUcal. of the correlation line between the basal uptake and the insulin effect. In this case, what is worth attention is the corre.lation line between MBUcal. and the glucose concentration in the incubation medium, which seems to pass approximately the original point. This is very suggestive in elucidating the mode of the physiological action of insulir since this finding indicates that the diaphragm has the ability to take up glucose so far as it is present.

Lundbaek and Stevenson (1948) performed experiments on the diaphragm method with animals given high- and non-carbohydrate diet, and Gilmore and Samuels (1949) and Hansen et al. (1951) with animals given high-carbohydrate and high-fat diet, and all observed that diaphragms from animals given high-carbohydrate diet showed higher basal uptake. The authors also found that diaphragms from the high-carbohydrate group gave higher basal uptake than those from the balanced diet group, and further that the former gave lower insulin effect. Moreover, it was confirmed that these changes were not deviations from the correlation line between the basal uptake and the insulin effect, but alterations along it (observation 4). And observation 5 leads one to consider the possibility that the above changes would be due to the insulinization to which the diaphragm was subjected in the body before sacrifice. Since the correlation curve by Kerly and Ottaway (1954) is the combination of values determined under different conditions of diet and fasting, the length of the fasting time may also be a condition which induces variation along the correlation line. And all the other conditions hitherto discussed are considered to elicit variations divergent from the correlation line. For example, variations in the temperature in the animal stock room seem to have a definite tendency to elicit a dislocation of the correlation line itself. Takeuchi (1958) reported that with rise in the temperature, increase in the basal uptake, insulin effect and oxygen consumption took place, and assumed that the correlation line obtained at different constant temperatures would nearly be in parallel relation. At any rate, it will be an important problem to clarify in what way the regression line between the basal uptake and the insulin effect would be affected by factors which have numerously been reported as bearing on glucose uptake by the diaphragm removed from the rat. 


\section{SUMMARY}

1. Relation between basal glucose uptake and the so-called insulin effect obtained by the rat-diaphragm method was investigated, and a linear correlation was confirmed within a definite range.

2. Change was produced in the properties of the correlation line by variations in the concentration of glucose or of insulin in the medium, and it was found that correlation lines were dislocated in a radiating form with the center on a definite point on the ordinate in the case of change in glucose concentration, and on the abscissa in the case of change in the insulin concentration. Attempt was made to use the slope of the correlation line as the metameter of log-dose response curve for insulin determination, and the following formulas were found for the regression line: $\mathrm{s}=0.212, \mathrm{~b}=+1.345, \lambda=0.158$.

3. Change in glucose uptake ability elicited by change in diet composition or by insulin pretreatment took place along the correlation line, whereas variation due to the procedure of preparation of the diaphragm or to that of the determination of glucose occurs independently of the correlation line.

\section{ACKNOWLEDGMENT}

The authors are grateful to Dr. Charles A. Winter, Merck Institute for Therapeutic Research, West Point, Pennsylvania, U.S.A., for his kind revision of the manuscript.

\section{REFERENGES}

Bliss, G. I. The Statistics of the Bioassay. Academic Press Inc., New York, (1952).

Brown, D. H., C. R. Park, W. H. Daughaday and M. Cornblath (1952). J. Biol. Chem. 197, 167. Gemill, G.L. (1940). Bull. Johns Hopkins Hosp. 66, 232.

Gilmore, R. G. and L. T. Samuels (1949). J. Biol. Chem. 181, 813.

Hansen, R. G., W. J. Rutter and L. T. Samuels (1951). J. Biol. Chem. 192, 243.

Kerly, M. and J. A. Ottaway (1954). J. Physiol. 123, 534.

Krahl, M. E. (1951). Ann. N. Y. Acad. Sci. 54, 649.

Krahl, M. E. and C. R. Park (1948). J. Biol. Chem. 174, 939.

Lundbaek, K. and J. A. F. Stevenson (1948). Federation Proc. 7, 75.

Randle, P. J. (1954). Brit. Med. J. 1, 1237.

Randle, P. J. (1956). J. Endocrinol. 14, 82.

Rogers, T. A. (1958). Proc. Soc. Exptl. Biol. Med. 97, 646.

Somogyi, M. (1945). J. Biol. Chem. 160, 69.

Stadie, W. G. and J. A. Zapp (1947). J. Biol. Chem. 170, 55.

Takeuchi, S. (1958). Folia. Endocrinol. Japon. 34, 13. (In Japanese)

Takeuchi, S., S. Ohashi and Y. Kobayashi (1957a). Folia Pharmacol. Japon. 53, 740. (In Japanese)

Takeuchi, S., S. Ohashi and Y. Kobayashi (1957b). J. Pharmacol. Exptl. Therap. 119, 437.

Vallance-Owen, J. and B. Hurlock (1954). Lancet 1, 68.

Willebrands, A. F. and J. Groen (1956). Diabetes 5, 378.

Willebrands, A. F., J. Groen, G. E. Kamminga and J. R. Blickman (1950). Science 112, 277. 